\title{
GCU
}

Glasgow Caledonian

University

University for the Common Good

\section{Fingerprinting of crude oil using fluorescence spectrometry}

Holmes-Smith, A. S.; Uttamlal, Mahesh; McCormick, C.; Hepburn, Donald; Graham, A.; Faichnie, D.

Published in:

Proceedings of SPIE Volume 8372: Ocean Sensing and Monitoring IV

DOI:

$10.1117 / 12.920604$

Publication date:

2012

Document Version

Publisher's PDF, also known as Version of record

Link to publication in ResearchOnline

Citation for published version (Harvard):

Holmes-Smith, AS, Uttamlal, M, McCormick, C, Hepburn, D, Graham, A \& Faichnie, D 2012, Fingerprinting of crude oil using fluorescence spectrometry. in WW Hou \& R Arnone (eds), Proceedings of SPIE Volume 8372: Ocean Sensing and Monitoring IV. SPIE, SPIE Ocean Sensing and Monitoring IV Conference, Baltimore, United States, 23/04/12. https://doi.org/10.1117/12.920604

\section{General rights}

Copyright and moral rights for the publications made accessible in the public portal are retained by the authors and/or other copyright owners and it is a condition of accessing publications that users recognise and abide by the legal requirements associated with these rights.

Take down policy

If you believe that this document breaches copyright please view our takedown policy at https://edshare.gcu.ac.uk/id/eprint/5179 for details of how to contact us. 


\title{
Fingerprinting of crude oil using fluorescence spectrometry
}

\author{
A. S. Holmes-Smith ${ }^{\mathrm{a}}$, M. Uttamlal ${ }^{\mathrm{a}}$, C. McCormick ${ }^{\mathrm{a}}$, D. M. Hepburn ${ }^{\mathrm{a}}$, A. Graham ${ }^{\mathrm{b}}$, D. Faichnie ${ }^{\mathrm{b}}$ \\ ${ }^{a}$ School of Engineering and Built Environment, Glasgow Caledonian University, Cowcaddens Road, \\ Glasgow G4 0BA, Scotland UK \\ ${ }^{\mathrm{b}}$ FMC Technologies Ltd, Coltness House, Bellshill, ML4 3RB, Scotland UK
}

\begin{abstract}
Crude oil is a complex mixture of hydrocarbons (e.g. paraffins, aromatics, napthenes), sulphur compounds (e.g. sulphur, sulphides), amines, metals (e.g. Ni, $\mathrm{Fe}$ ) and salts (e.g. $\mathrm{NaCl}$, sand). Quantitative chemical analysis of such combinations is difficult and requires partial or complete separation of the components, challenging outside of the laboratory. Qualitative chemical analysis of oil is simpler using techniques such fluorescence spectroscopy. In this paper we will present fluorescence (spectra and lifetime) data for crude oil samples of varying (specific) API gravity and show how qualitative chemical information can be extracted from the spectra. This will include data obtained using synchronous scanning fluorescence spectrometry (SS) and time-resolved emission spectroscopy (TRES) and demonstrate the ability of utilising these methods to obtain better qualitative chemical information and hence the ability to "fingerprint" crude oil.
\end{abstract}

Keywords: crude oil, fluorescence, synchronous scan, TRES

\section{INTRODUCTION}

The complex nature of crude oil, being a mixture of hydrocarbons, sulphur compounds, amines and metals, can result in complex and lengthy chemical analysis methods. The analysis of crude oil using fluorescence techniques has become popular in recent years due to the highly fluorescent nature of the constituent components of crude oil ${ }^{1-5}$. This has allowed the development of in-situ methods of oil detection in the environment using, for examples, LIDAR techniques. Fluorescence methodologies have been used to detect crude oil in the marine environment ${ }^{6,7}$ and in crude oil extraction and petroleum fraction determination ${ }^{2}$.

Fluorescence is the radiative transition of an electron from the first excited singlet state of a molecule back to the ground state, following absorption of a higher energy photon. The fluorescence properties of each fluorescing molecule are unique to that molecule and this allows the use of fluorescence based techniques to develop a 'fluorescence fingerprint' of each crude oil sample. Crude oils contain a complex mixture of fluorescent compounds where the excitation of one constituent molecule can lead to various de-excitation pathways. Following initial excitation of component A to state $\mathrm{A}^{*}$ by absorption of a photon, the following reactions and interactions between component molecules $\mathrm{A}$ and $\mathrm{B}$ are possible, assuming the fluorescence emission of component $\mathrm{A}$ has spectral overlap with the absorption spectrum of component B:

$\begin{array}{ll}\mathrm{A}^{*} \rightarrow \mathrm{A}+\mathrm{h} v_{1} & \text { Radiative decay of component A } \\ \mathrm{B}+\mathrm{h} v_{1} \rightarrow \mathrm{B}^{*} & \text { Absorption of the emitted photon by component B } \\ \mathrm{A}^{*}+\mathrm{B} \rightarrow \mathrm{A}+\mathrm{B}^{*} & \text { Non-radiative energy transfer from A to B } \\ \mathrm{B}^{*} \rightarrow \mathrm{B}+\mathrm{h} v_{2} & \text { Radiative decay of component B } \\ \mathrm{A}^{*}+\mathrm{Q} \rightarrow \mathrm{A}+\mathrm{Q} & \text { Collisional quenching of component A by a quenching molecule, Q. (Non radiative process) }\end{array}$

The energy transfer process can continue to other molecules in the mixture which have the required spectral overlap and are within the critical distance for energy transfer to occur. The effect of the energy transfer and collisional quenching processes is to decrease the recovered fluorescence intensity and lifetimes obtained. Excitation at short wavelengths results in a mixture of all these deactivation pathways compared to excitation at longer wavelengths where collisional quenching may dominate over energy transfer.

Ocean Sensing and Monitoring IV, edited by Weilin Will Hou,

Robert Arnone, Proc. of SPIE Vol. 8372, 83720D @ 2012 SPIE

CCC code: $0277-786 X / 12 / \$ 18 \cdot$ doi: $10.1117 / 12.920604$

Proc. of SPIE Vol. 8372 83720D-1 
The fluorescence techniques that have been reported in the literature for application to crude oil analysis are fluorescence emission spectroscopy, synchronous scanning fluorescence spectroscopy ${ }^{8,} 9$ and time-resolved fluorescence spectroscopy ${ }^{3,4,10}$. Attempts at correlating the change in the fluorescence properties of the crude oil samples with an aspect of the crude oil, e.g. API value, aromatic, asphaltene and / or sulphur content have had varying degrees of success. The first report of using synchronous scanning for the identification of crude oil was in 1976 by P. John and I Soutar ${ }^{8}$ where it was suggested that this methodology held promise for identification of oil spillages in the marine environment. Later work by A.G. Ryder has concentrated on time-resolved methods for crude oil identification ${ }^{3,4}$. Fluorescence lifetime studies have predominately described the decay kinetics as a series of exponential functions with the average value for the fluorescence lifetime being used to determine some correlation with crude oil samples. This is really a simplification of the decay pathways that exist but, nevertheless, indicates differences in oils.

This work investigated both steady-state and time-resolved approaches to fluorescence in oils, with the aim of developing a method of fingerprinting crude oil samples. Differences in fluorescence and synchronous scan spectra obtained from the oils diluted in a range of solvents show some degree of discrimination. The application of second derivative synchronous scanning fluorescence spectroscopy using a range of wavelength differences demonstrates further discrimination. To date, measurement of diluted crude oil samples has concentrated on using hexane as the solvent. The fluorescence decay kinetics of the crude oil samples are analysed using a non-extensive distribution method, which has previously been successfully applied to the study of energy transfer in complex protein samples ${ }^{11}$. Time-resolved emission spectra (TRES) for the different crude oil samples show an enhanced variation between the spectral components of the different oil samples studied.

\section{METHODOLOGY}

\subsection{Sample Preparation}

Three crude oil samples were supplied by FMC Technologies, two were identified by their API value (35 and 21) and a third was stabilised crude oil, labelled STAB crude. The geographic origin of these crude oils is not known. For the diluted samples $0.5 \mathrm{~g}$ of the crude oil was dissolved in $10 \mathrm{ml}$ of the chosen solvent, followed by a further dilution of 10 $\mu \mathrm{l}$ of the dissolved component in a further $10 \mathrm{ml}$ of the solvent. In the case of methanol, where less of the crude oil dissolved, $50 \mu \mathrm{l}$ was taken for the further dilution step to achieve a similar fluorescence intensity when compared to the other solvents. All solvents were used as received from the supplier, Fisher Scientific. All measurements were performed in $1 \mathrm{~cm}$ quartz cells on samples at STP. Undiluted crude oil samples were measured in a thin sample holder and the fluorescence measured using front face excitation at an angle of $45^{\circ}$.

\subsection{Instrumentation}

Steady-state fluorescence spectra and synchronous scan spectra were obtained using a SPEX Fluoromax 2 fluorimeter. Slit bandwidths were $2 \mathrm{~nm}$ for both excitation and emission monochromators. All signals recorded were a ratio of signal to reference to correct for any lamp variations. Spectra were corrected for any solvent Raman bands by subtraction of the signal obtained when measuring the solvent on its own.

Time-resolved measurements were performed on a HORIBA Jobin Yvon (IBH) Ltd 5000U spectrometer. The excitation source employed was a co-axial nanosecond flashlamp with the following conditions: electrode gap $0.95 \mathrm{~mm}$, hydrogen $\left(\mathrm{H}_{2}\right)$ gas pressure $0.5 \mathrm{Bar}$, Voltage $7 \mathrm{kV}$ and repetition rate $40 \mathrm{kHz}$. Unless otherwise stated the time calibration was set to $0.224 \mathrm{~ns} /$ channel. Fluorescence decays were collected until there were 10000 counts in the peak channel. For TRES, the excitation wavelength was $300 \mathrm{~nm}$ and data was collected every $5 \mathrm{~nm}$ over the wavelength range $330 \mathrm{~nm}-600 \mathrm{~nm}$ with a dwell time at each wavelength of $120 \mathrm{~s}$.

\subsection{Data Analysis}

The second derivative synchronous scan spectra was calculated using the spectra manipulation program, Spekwin32. Analysis was performed on spectra which had been corrected for solvent Raman peaks and the data smoothed using the smoothing function in this programme. 
Fluorescence decays were analysed using DAS6 software from HORIBA Jobin Yvon (IBH) Ltd. A multi-exponential model, Equation (1), was used to fit the data:

$$
I(t)=\sum_{i=1}^{n} B_{i} e^{-t / \tau_{i}}
$$

where $\mathrm{I}(\mathrm{t})$ is the intensity at time, $\mathrm{t}, \mathrm{B}_{\mathrm{i}}$ is the pre-exponential component and $\tau$ is the fluorescence lifetime. Data were analysed using either a 3 or 4 exponential model with the $\chi^{2}$ value and the residual plot used to assess the goodness of fit. The contribution of each component to the overall decay was determined using Equation (2):

$$
\alpha_{i}=\frac{B_{i}}{\sum B_{i}}
$$

and the average lifetime calculated according to Equation (3):

$$
\langle\tau\rangle=\sum \alpha_{i} \tau_{i}
$$

In the case of the TRES measurements the data curves were fit globally to a 3 exponential model and the pre-exponential value, $B_{i}$, plotted as a function of wavelength.

Given that crude oil is a complex mixture of fluorophores, the data were also analysed using a distribution model based on non-extensive statistics ${ }^{12}$. This model has been used to describe fluorescence decays by Wlodarczyk et $\mathrm{al}^{11,13}$, Kierdaszuk $^{14}$ and Rolinski and Birch ${ }^{15}$. The distribution model is given by Equation (4):

$$
I(t)=A+\sum_{i=1}^{n} B_{i}\left[1-\left(1-q_{i}\right) t / \tau_{i}\right]^{\frac{1}{1-q_{i}}}
$$

where $\mathrm{k}=1$ to $5, \tau_{\mathrm{i}}$ is the mean value of the lifetime distribution and $\mathrm{q}$ is a parameter of heterogeneity given by Equation (5):

$$
q=1+\frac{2}{N}=1+\frac{\left\langle\langle\gamma-\langle\gamma\rangle\rangle^{2}\right\rangle}{\langle\gamma\rangle^{2}}
$$

which describes the fluctuation according to a $\gamma$ function which is also indicative of the width of the distribution and the number of decay channels, $\mathrm{N}$. In the case where $\mathrm{q} \rightarrow 1$, then the decay is exponential.

\section{RESULTS \& DISCUSSION}

\subsection{Fluorescence spectra}

The fluorescence spectra of crude oil have been widely reported in the literature ${ }^{1,2,16}$. As shown in Figure 1, the fluorescence spectra of one of the crude oil samples dissolved in hexane are very dependent on excitation wavelength, and are broad and featureless in composition. The peak emission wavelength is dependent on the excitation wavelength, but the shape of the spectra at the longer wavelengths is the same. This is due to energy transfer process occurring within the complex mixture of fluorophores. Using this form of analysis, fluorescence spectra are only really useful for confirming that crude oil is present in a sample, with discrimination between crude oil samples difficult.

The fluorescent components within a crude oil dissolve by differing amounts in the various solvents investigated, i.e. the components extracted from the base oil are dependent upon the solvent. The variation in fluorescence spectra for the extracted compounds is demonstrated in the emission spectra for API21 crude oil dissolved in hexane, cyclohexane, methanol, dichloromethane (DCM), dimethylformaldehyde (DMF) and toluene for excitation at 300nm is shown in Figure 2. The two non-polar solvents, hexane and cyclohexane give similar emission spectra as expected. The concentration of fluorescence species dissolved in methanol and DMF is much less than that for the other solvents as evidenced by the paler colour observed in the samples and the reduced fluorescence intensity obtained for these 
solutions: note as the data in Figure 2 has been normalised at the peak emission wavelength it does not show the reduced intensity, but indicates the differences in spectral shape and hence the different dissolved components in each solvent.

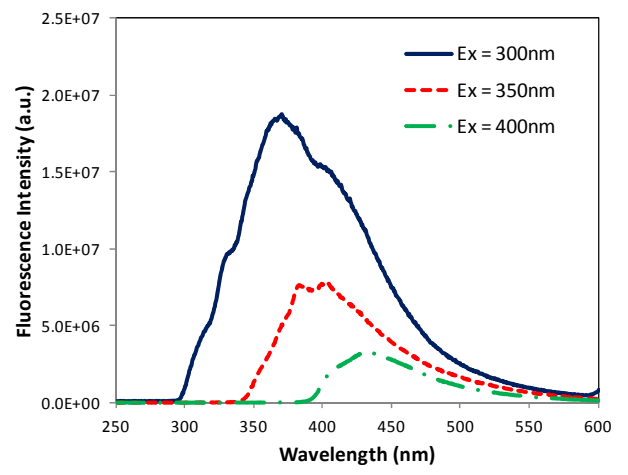

Figure 1. API35 in hexane: emission spectra at different excitation wavelengths

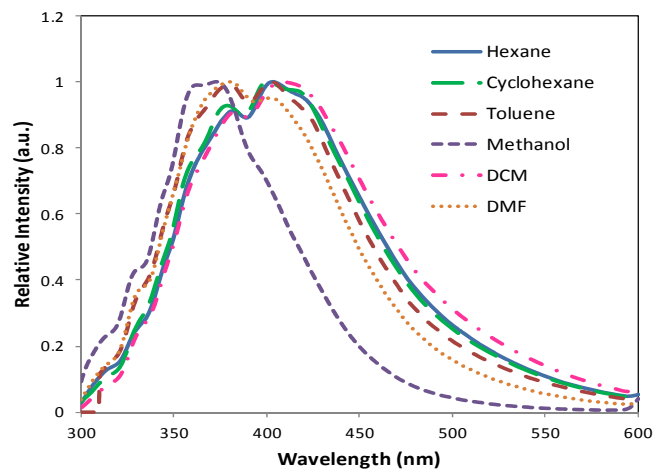

Figure 2. API21 in different solvents, $E x=300 \mathrm{~nm}$, Spectra have been normalised at peak emission wavelength.

\subsection{Synchronous scan (SS) fluorescence spectra}

Synchronous scan spectra give much more detailed spectra, as shown in Figure 3, compared to Figures 1 and 2. Differences between the spectra of the three oils become more apparent. Figure 3(a) shows the spectra obtained when the difference in wavelength between the excitation and emission monochromator is $5 \mathrm{~nm}$, where information on the fluorescent components which have been directly excited by the excitation light can be determined. Spectra collected with a greater difference between the excitation and emission wavelengths, e.g. Figure 3(b) where $\Delta \lambda$ is $25 \mathrm{~nm}$, will have a mixture of fluorescence from direct excitation of the fluorophore and energy transfer to another fluorescent species emitting at a longer wavelength.

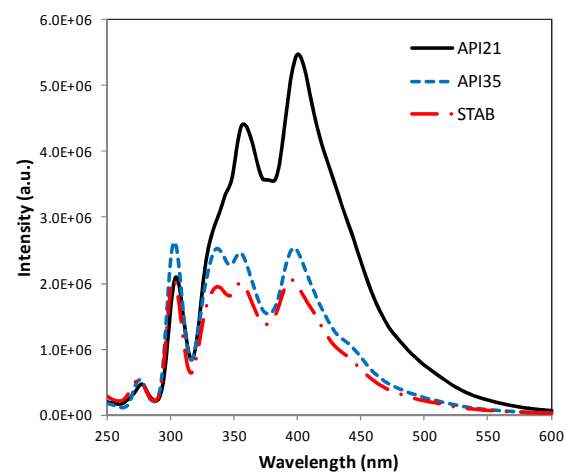

(a)

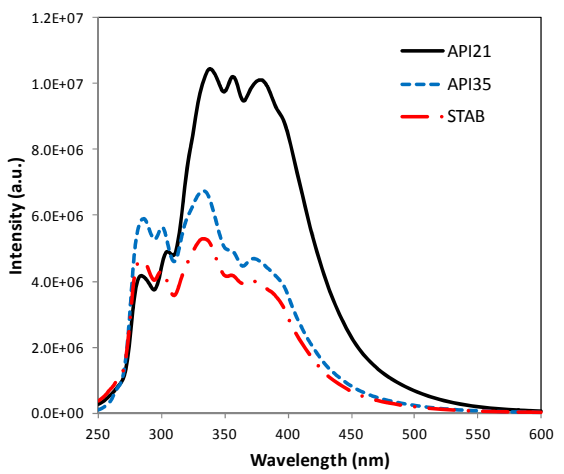

(b)

Figure 3. Synchronous scans for crude oil samples in hexane (a) $\Delta \lambda=5 \mathrm{~nm}$ (b) $\Delta \lambda=25 \mathrm{~nm}$

In order to highlight the differences between the SS spectra the second derivative of each spectrum was calculated, examples of the spectra obtained are given in Figure 4. Again the spectral differences obtained for the same crude oil sample in different solvents is clear, particularly for the scan with $\Delta \lambda=25 \mathrm{~nm}$ (Figure 4(b)). Table 1 gives the location of the first 3 positive peaks obtained for the spectra in Figure 4(b) and the ratio of the subsequent peak heights to the first peak. It is clear from the data in Table 1 and Figure 4(b) that dissolving the crude oil samples in toluene and methanol gives very different spectra when compared to the other solvents used. This is particularly evident in the position of the first peak, Toluene is shifted by $+6 \mathrm{~nm}$ and Methanol by $-2 \mathrm{~nm}$ relative to that obtained in hexane. The differences indicating variation in dissolved components in the solvents. In contrast the position of the second and third peaks is relatively unchanged with solvent. The ratio of the peak heights varies with all solvents, giving information on the concentration of the dissolved components emitting at these wavelengths. Comparing the crude oil samples in the same solvents, Figures 4(c) and 4(d), the ratio of peak heights is clearly different for the API21 and API35 samples. STAB 
crude and API35 show similar spectral features and here solvent plays a more crucial role in differentiating between the samples, with the biggest difference in peak ratios between crude oil samples being noted for DCM and DMF. Variation in peak positions and peak height ratios for the three oils in DCM, using $\Delta \lambda$ of $70 \mathrm{~nm}$, can be seen in Figure 4(d). The biggest difference between the spectra is between $305-315 \mathrm{~nm}$ where a positive peak is obtained for API35 and STAB crude oil samples and a negative peak for API 21.

Table 1. Peak positions and relative intensities for $2^{\text {nd }}$ derivative synchronous scan spectra with $\Delta \lambda=25 \mathrm{~nm}$

\begin{tabular}{|c|c|c|c|c|c|c|c|c|c|}
\hline Solvent & $\begin{array}{l}\text { API21 } \\
\lambda_{\mathrm{p}}(1) / \mathrm{nm}\end{array}$ & $\begin{array}{c}\lambda_{\mathrm{p}}(2) / \mathrm{nm} \\
\left(\mathrm{I}_{2} / \mathrm{I}_{1}\right)\end{array}$ & $\begin{array}{c}\lambda_{\mathrm{p}}(3) / \mathrm{nm} \\
\left(\mathrm{I}_{3} / \mathrm{I}_{1}\right)\end{array}$ & $\begin{array}{l}\text { API35 } \\
\lambda_{\mathrm{p}}(1) / \mathrm{nm}\end{array}$ & $\begin{array}{c}\lambda_{\mathrm{p}}(2) / \mathrm{nm} \\
\left(\mathrm{I}_{2} / \mathrm{I}_{1}\right)\end{array}$ & $\begin{array}{c}\lambda_{\mathrm{p}}(3) / \mathrm{nm} \\
\left(\mathrm{I}_{3} / \mathrm{I}_{1}\right)\end{array}$ & $\begin{array}{l}\text { STAB } \\
\lambda_{\mathrm{p}}(1) / \mathrm{nm}\end{array}$ & $\begin{array}{c}\lambda_{\mathrm{p}}(2) / \mathrm{nm} \\
\left(\mathrm{I}_{2} / \mathrm{I}_{1}\right)\end{array}$ & $\begin{array}{c}\lambda_{\mathrm{p}}(3) / \mathrm{nm} \\
\left(\mathrm{I}_{3} / \mathrm{I}_{1}\right)\end{array}$ \\
\hline Hexane & 272 & $\begin{array}{c}295 \\
(0.74)\end{array}$ & $\begin{array}{c}311 \\
(1.10)\end{array}$ & 272 & $\begin{array}{c}293 \\
(0.54)\end{array}$ & $\begin{array}{c}310 \\
(0.72)\end{array}$ & 271 & $\begin{array}{c}293 \\
(0.55)\end{array}$ & $\begin{array}{c}310 \\
(0.61)\end{array}$ \\
\hline Cyclohexane & 271 & $\begin{array}{c}294 \\
(1.43)\end{array}$ & $\begin{array}{c}311 \\
(1.80)\end{array}$ & 270 & $\begin{array}{c}293 \\
(0.79)\end{array}$ & $\begin{array}{c}310 \\
(1.00)\end{array}$ & 270 & $\begin{array}{c}293 \\
(0.79)\end{array}$ & $\begin{array}{c}310 \\
(1.03)\end{array}$ \\
\hline Methanol & 270 & $\begin{array}{c}293 \\
(0.80)\end{array}$ & $\begin{array}{c}3.10 \\
(1.02)\end{array}$ & 270 & $\begin{array}{c}291 \\
(0.44)\end{array}$ & $\begin{array}{c}309 \\
(0.69)\end{array}$ & 270 & $\begin{array}{c}292 \\
(0.50)\end{array}$ & $\begin{array}{c}308 \\
(0.72)\end{array}$ \\
\hline Toluene & 278 & $\begin{array}{c}295 \\
(0.47)\end{array}$ & $\begin{array}{c}3.12 \\
(0.64)\end{array}$ & 279 & $\begin{array}{c}294 \\
(0.17)\end{array}$ & $\begin{array}{c}311 \\
(0.42)\end{array}$ & 279 & $\begin{array}{c}294 \\
(0.22)\end{array}$ & $\begin{array}{c}312 \\
(0.44)\end{array}$ \\
\hline DCM & 272 & $\begin{array}{c}295 \\
(1.53)\end{array}$ & $\begin{array}{c}312 \\
(1.84)\end{array}$ & 272 & $\begin{array}{c}294 \\
(0.66)\end{array}$ & $\begin{array}{c}311 \\
(0.92)\end{array}$ & 271 & $\begin{array}{c}293 \\
(0.75)\end{array}$ & $\begin{array}{c}311 \\
(1.02)\end{array}$ \\
\hline DMF & 272 & $\begin{array}{c}295 \\
(1.13)\end{array}$ & $\begin{array}{c}312 \\
(1.33)\end{array}$ & 272 & $\begin{array}{c}294 \\
(0.75)\end{array}$ & $\begin{array}{c}311 \\
(1.02)\end{array}$ & 271 & $\begin{array}{c}292 \\
(0.92)\end{array}$ & $\begin{array}{c}310 \\
(0.99)\end{array}$ \\
\hline
\end{tabular}

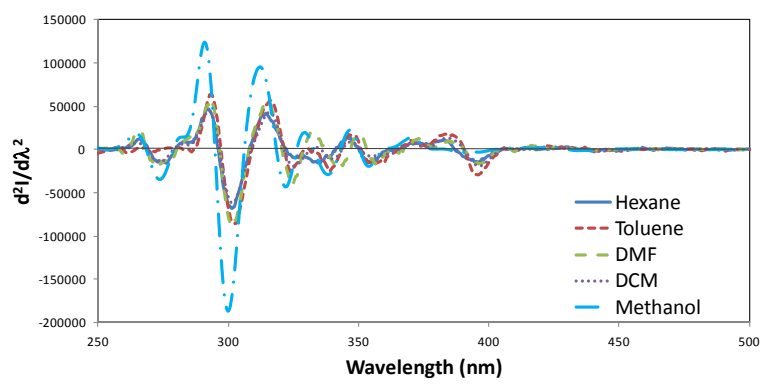

(a)

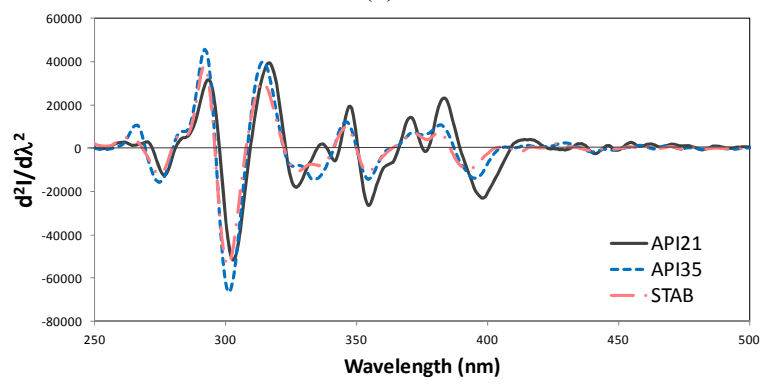

(c)

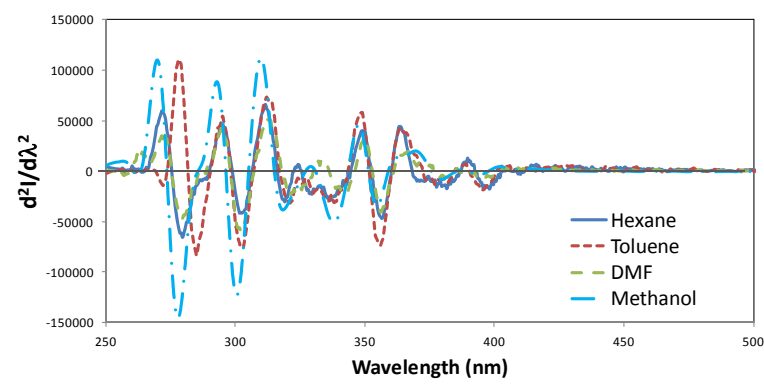

(b)

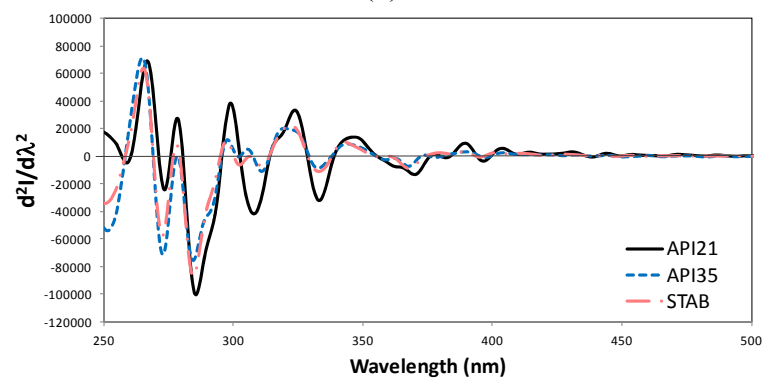

(d)

Figure 4. $2^{\text {nd }}$ Derivative synchronous scan spetcra for (a) API35 in different solvents, $\Delta \lambda=5 \mathrm{~nm}$, (b) API21 in different solvents with $\Delta \lambda=25 \mathrm{~nm}$ (c) All crude oil samples in hexane, $\Delta \lambda=5 \mathrm{~nm}$, (d) All crude oil samples in DCM, $\Delta \lambda=70 \mathrm{~nm}$,

\subsection{Fluorescence Lifetime}

The fluorescence lifetimes of samples were determined at an excitation wavelength of $300 \mathrm{~nm}$ and emission wavelengths $400 \mathrm{~nm}$ and $450 \mathrm{~nm}$ and the results of the analysis in terms of a sum of exponentials, Equation (1), are given in Table 2. The values of the fluorescence lifetimes for oils diluted in hexane, labelled API21 API35 and STAB in Table 2, are very 
similar at each of the excitation / emission wavelength combinations studied. The fluorescence lifetime values obtained at the longer emission wavelength have a small percentage of a longer lifetime component. For the undiluted crude oil samples, labelled API21-N, API35-N and STAB-N in Table 2 and subsequent Tables/Figures, the average lifetime is much greater and the emergence of a longer fluorescence emission is noted. Indeed, for the undiluted samples a fourth exponential term, of low intensity, was required to adequately fit the data in the majority of cases. When the fluorescence emission is monitored at longer wavelengths $\langle\tau\rangle$ is greater, consistent with average fluorescence lifetime values reported by others ${ }^{16}$. Also the values obtained for undiluted samples are greater. The greater difference for the $\langle\tau\rangle$ values for API35-N and STAB-N clearly shows that discrimination between these crude oils based on fluorescence lifetime is possible.

Given that crude oil samples are a complex mix of fluorescing species, it is appropriate to analyse the data using the distribution model, Equation (4). Figure 5 shows the fluorescence decay and the residual plots for API35 in hexane showing that both the multi-exponential model and distribution decay give good fits to the data. Table 3 gives the fitted parameters obtained using Equation (4) and Figure 6 shows the distribution fits obtained.

Clear differences between the distributions obtained in Figure 6 are evident for the different crude oil samples. In the majority of cases the contribution to the decay process, as given by the value for $\alpha$, is greatest for the shortest lifetime component for both multi-exponential and non-extensive distribution analysis. This is to be expected as this component is likely to be due to the various quenching processes that are occurring within the crude oil samples. The low value for $\mathrm{q}$ in some cases indicates that the decay is almost monoexponential in nature, i.e. $\mathrm{q}=1.01$ and the distribution is narrower as observed in Figure 6.

Table 2. Fluorescence lifetime parameters obtained using a multi-exponential model, Equation (1).

* denotes time calibration was $0.48 \mathrm{~ns} /$ channel

\begin{tabular}{|c|c|c|c|c|c|c|c|c|c|c|}
\hline \multicolumn{11}{|c|}{$\underline{\lambda}_{\mathrm{ex}}=300 \mathrm{~nm}: \lambda_{\mathrm{em}}=400 \mathrm{~nm}$} \\
\hline $\begin{array}{c}\text { Crude } \\
\text { Oil }\end{array}$ & $\tau_{1} / \mathrm{ns}$ & $\tau_{2} / \mathrm{ns}$ & $\tau_{3} / \mathrm{ns}$ & $\tau_{4} / \mathrm{ns}$ & $\alpha_{1}$ & $\alpha_{2}$ & $\alpha_{3}$ & $\alpha_{4}$ & $<\tau>/ \mathrm{ns}$ & $\chi^{2}$ \\
\hline API21 & $0.89 \pm 0.21$ & $3.16 \pm 0.78$ & $6.38 \pm 0.18$ & & 0.40 & 0.39 & 0.20 & & 2.91 & 1.05 \\
\hline API35 & $0.63 \pm 0.58$ & $2.67 \pm 0.24$ & $6.39 \pm 0.15$ & & 0.38 & 0.44 & 0.18 & & 2.55 & 0.99 \\
\hline STAB & $0.92 \pm 0.30$ & $3.17 \pm 0.33$ & $6.79 \pm 0.21$ & & 0.48 & 0.38 & 0.13 & & 2.57 & 0.96 \\
\hline $\begin{array}{c}\text { API21- } \\
\mathrm{N}^{*}\end{array}$ & $1.42 \pm 0.15$ & $6.2 \pm 1.0$ & $27.1 \pm 2.4$ & $77.2 \pm 4.2$ & 0.63 & 0.28 & 0.08 & 0.01 & 5.82 & 1.07 \\
\hline $\begin{array}{c}\text { API35- } \\
\text { N }\end{array}$ & $0.63 \pm 0.54$ & $2.6 \pm 0.3$ & $8.1 \pm 0 . \mathrm{s}$ & $26.7 \pm 2.4$ & 0.53 & 0.34 & 0.12 & 0.02 & 3.30 & 1.12 \\
\hline $\begin{array}{l}\text { STAB- } \\
\mathrm{N}^{*}\end{array}$ & $1.83 \pm 0.24$ & $7.3 \pm 0.9$ & $26.1 \pm 1.5$ & $82.2 \pm 5.1$ & 0.48 & 0.37 & 0.14 & 0.01 & 8.24 & 1.03 \\
\hline \multicolumn{11}{|c|}{$\underline{\lambda}_{\mathrm{ex}}=300 \mathrm{~nm}: \lambda_{\mathrm{em}}=450 \mathrm{~nm}$} \\
\hline $\begin{array}{c}\text { Crude } \\
\text { Oil }\end{array}$ & $\tau_{1} / \mathrm{ns}$ & $\tau_{2} / \mathrm{ns}$ & $\tau_{3} / \mathrm{ns}$ & $\tau_{4} / \mathrm{ns}$ & $\alpha_{1}$ & $\alpha_{2}$ & $\alpha_{3}$ & $\alpha_{4}$ & $<\tau>/ \mathrm{ns}$ & $\chi^{2}$ \\
\hline API21 & $1.58 \pm 0.21$ & $4.71 \pm 0.18$ & $13.8 \pm 0.9$ & & 0.49 & 0.49 & 0.03 & & 3.41 & 1.06 \\
\hline API35 & $1.76 \pm 0.27$ & $5.01 \pm 0.21$ & $15.1 \pm 0.9$ & & 0.55 & 0.42 & 0.02 & & 3.43 & 1.02 \\
\hline STAB & $1.62 \pm 0.24$ & $4.81 \pm 0.21$ & $14.4 \pm 0.9$ & & 0.57 & 0.41 & 0.02 & & 3.20 & 0.91 \\
\hline $\begin{array}{l}\text { API21- } \\
\mathrm{N}^{*}\end{array}$ & $1.30 \pm 0.18$ & $6.0 \pm 1.5$ & $20.7 \pm 1.8$ & $57.5 \pm 3.3$ & 0.58 & 0.30 & 0.11 & 0.02 & 5.81 & 1.04 \\
\hline $\begin{array}{c}\text { API35- } \\
\text { N }\end{array}$ & $3.90 \pm 0.30$ & $10.9 \pm 0.6$ & $29.4 \pm 0.9$ & & 0.65 & 0.30 & 0.04 & & 7.13 & 1.06 \\
\hline $\begin{array}{l}\text { STAB- } \\
\mathrm{N}^{*}\end{array}$ & $5.4 \pm 1.2$ & $13.3 \pm 3.3$ & $29.5 \pm 2.1$ & $71 \pm 12$ & 0.49 & 0.34 & 0.15 & 0.02 & 13.2 & 1.08 \\
\hline
\end{tabular}



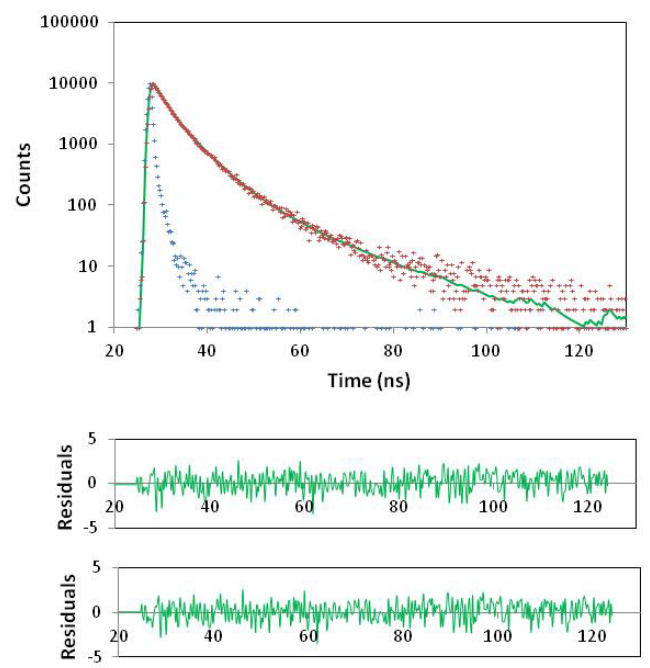

Figure 5. API 35 diluted in hexane, $\lambda_{\mathrm{ex}}=300 \mathrm{~nm}, \lambda_{\mathrm{em}}=450 \mathrm{~nm}$ Top: Fluorescence decay (red crosses), Instrument response function (blue crosses, FWHM 1.07 ns), Fitted function (green line) Middle: Residual plot for 3 exponential analysis (Equation 1 with n=3) Bottom: Residual plot for analysis using Equation (4)

Table 3. Fluorescence lifetime parameters obtained using distribution model, Equation (4)

* denotes time calibration was $0.48 \mathrm{~ns} /$ channel

\begin{tabular}{|c|c|c|c|c|c|c|c|c|c|c|}
\hline \multicolumn{11}{|c|}{$\underline{\lambda}_{\mathrm{ex}}=300 \mathrm{~nm}: \lambda_{\mathrm{em}}=400 \mathrm{~nm}$} \\
\hline $\begin{array}{l}\text { Crude } \\
\text { Oil }\end{array}$ & $\begin{array}{c}\tau_{1} / \mathrm{ns} \\
\left(\alpha_{1}\right)\end{array}$ & $\begin{array}{c}\tau_{2} / \mathrm{ns} \\
\left(\alpha_{2}\right)\end{array}$ & $\begin{array}{c}\tau_{3} / \mathrm{ns} \\
\left(\alpha_{3}\right)\end{array}$ & $\mathrm{q}_{1}$ & $\mathrm{q}_{2}$ & $\mathrm{q}_{3}$ & $\mathrm{FWHM}_{1}$ & $\mathrm{FWHM}_{2}$ & $\mathrm{FWHM}_{3}$ & $\chi^{2}$ \\
\hline API21 & $\begin{array}{c}1.48 \\
(0.56)\end{array}$ & $\begin{array}{c}4.88 \\
(0.44)\end{array}$ & & 1.12 & 1.05 & & 1.59 & 2.80 & & 1.06 \\
\hline API35 & $\begin{array}{c}1.72 \\
(0.72)\end{array}$ & $\begin{array}{c}5.40 \\
(0.28)\end{array}$ & & 1.14 & 1.04 & & 2.11 & 2.59 & & 1.06 \\
\hline STAB & $\begin{array}{c}1.40 \\
(0.62)\end{array}$ & $\begin{array}{c}4.60 \\
(0.38)\end{array}$ & & 1.09 & 1.07 & & 1.20 & 3.35 & & 1.07 \\
\hline $\begin{array}{l}\text { API21- } \\
\mathrm{N}^{*}\end{array}$ & $\begin{array}{c}1.95 \\
(0.83)\end{array}$ & $\begin{array}{c}14.1 \\
(0.15)\end{array}$ & $\begin{array}{c}56.7 \\
(0.02)\end{array}$ & 1.30 & 1.30 & 1.03 & 5.34 & 38.7 & 25.1 & 1.13 \\
\hline $\begin{array}{c}\text { API35- } \\
\text { N }\end{array}$ & $\begin{array}{c}1.18 \\
(0.56)\end{array}$ & $\begin{array}{c}3.80 \\
(0.42)\end{array}$ & $\begin{array}{c}22.5 \\
(0.02)\end{array}$ & 1.01 & 1.26 & 1.04 & 0.30 & 8.44 & 11.7 & 1.13 \\
\hline $\begin{array}{c}\text { STAB- } \\
\mathrm{N}^{*}\end{array}$ & $\begin{array}{c}3.25 \\
(0.79) \\
\end{array}$ & $\begin{array}{c}19.2 \\
(0.20) \\
\end{array}$ & $\begin{array}{c}63.8 \\
(0.01) \\
\end{array}$ & 1.30 & 1.14 & 1.12 & 8.9 & 23.6 & 65.2 & 1.10 \\
\hline \multicolumn{11}{|c|}{$\underline{\lambda}_{\mathrm{ex}}=300 \mathrm{~nm}: \lambda_{\mathrm{em}}=450 \mathrm{~nm}$} \\
\hline $\begin{array}{l}\text { Crude } \\
\text { Oil }\end{array}$ & $\begin{array}{c}\tau_{1} / \mathrm{ns} \\
\left(\alpha_{1}\right)\end{array}$ & $\begin{array}{c}\tau_{2} / \mathrm{ns} \\
\left(\alpha_{2}\right)\end{array}$ & $\begin{array}{c}\tau_{3} / \mathrm{ns} \\
\left(\alpha_{3}\right)\end{array}$ & $\mathrm{q}_{1}$ & $\mathrm{q}_{2}$ & $\mathrm{q}_{3}$ & $\mathrm{FWHM}_{1}$ & $\mathrm{FWHM}_{2}$ & $\mathrm{FWHM}_{3}$ & $\chi^{2}$ \\
\hline API21 & $\begin{array}{c}1.59 \\
(0.56)\end{array}$ & $\begin{array}{c}4.81 \\
(0.41)\end{array}$ & $\begin{array}{c}13.9 \\
(0.04)\end{array}$ & 1.14 & 1.01 & 1.01 & 1.91 & 1.16 & 3.5 & 1.03 \\
\hline API35 & $\begin{array}{c}1.69 \\
(0.62)\end{array}$ & $\begin{array}{c}4.66 \\
(0.37)\end{array}$ & $\begin{array}{c}17.1 \\
(0.01)\end{array}$ & 1.19 & 1.06 & 1.01 & 2.63 & 3.19 & 4.1 & 0.94 \\
\hline STAB & $\begin{array}{c}1.18 \\
(0.35)\end{array}$ & $\begin{array}{c}3.43 \\
(0.64)\end{array}$ & $\begin{array}{c}14.5 \\
(0.01)\end{array}$ & 1.01 & 1.15 & 1.09 & 0.30 & 4.32 & 11.9 & 0.84 \\
\hline $\begin{array}{l}\text { API21- } \\
\mathrm{N}^{*}\end{array}$ & $\begin{array}{c}1.89 \\
(0.76)\end{array}$ & $\begin{array}{c}11.9 \\
(0.23)\end{array}$ & $\begin{array}{c}44.9 \\
(0.01)\end{array}$ & 1.30 & 1.26 & 1.04 & 5.17 & 26.5 & 23.4 & 1.06 \\
\hline $\begin{array}{c}\text { API35- } \\
\text { N }\end{array}$ & $\begin{array}{c}3.89 \\
(0.67)\end{array}$ & $\begin{array}{c}10.8 \\
(0.29)\end{array}$ & $\begin{array}{c}29.1 \\
(0.04)\end{array}$ & 1.03 & 1.02 & 1.01 & 1.6 & 3.8 & 7.0 & 1.05 \\
\hline $\begin{array}{l}\text { STAB- } \\
\mathrm{N}^{*}\end{array}$ & $\begin{array}{c}5.65 \\
(0.51)\end{array}$ & $\begin{array}{c}15.9 \\
(0.47)\end{array}$ & $\begin{array}{c}31.3 \\
(0.02)\end{array}$ & 1.02 & 1.17 & 1.03 & 1.9 & 22.8 & 25.8 & 1.06 \\
\hline
\end{tabular}




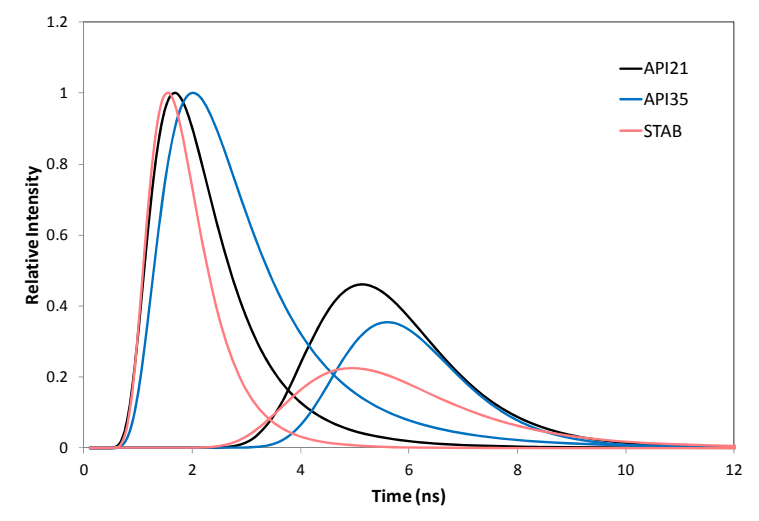

(a)

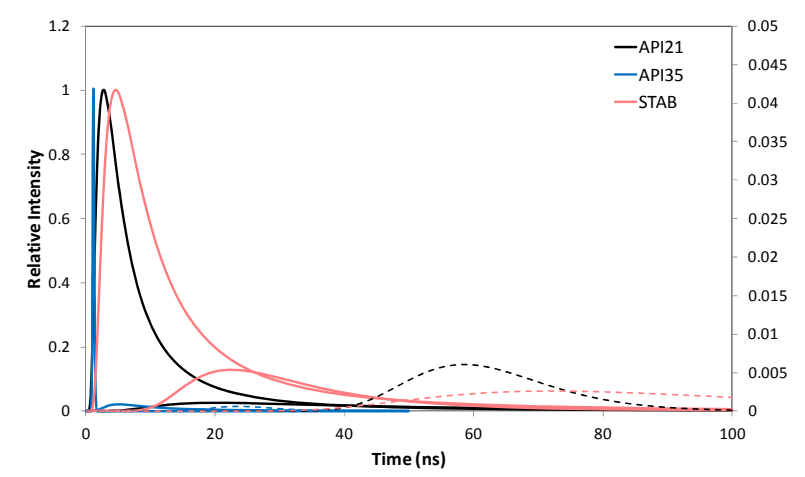

(c)

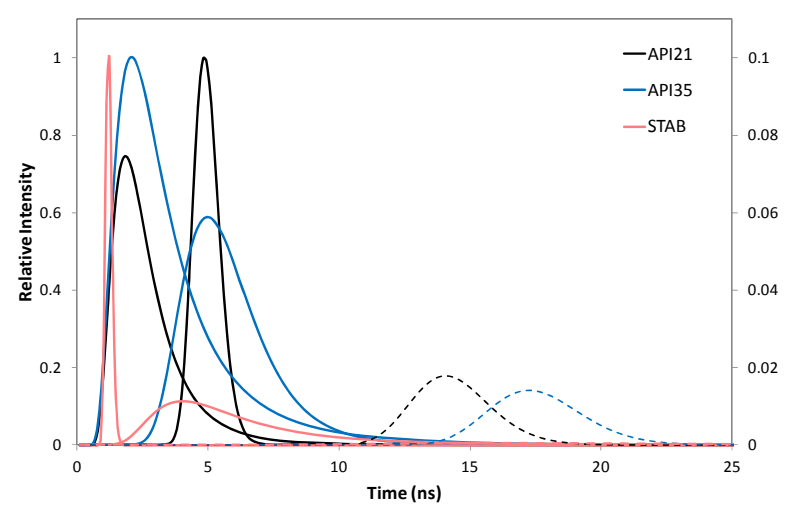

(b)

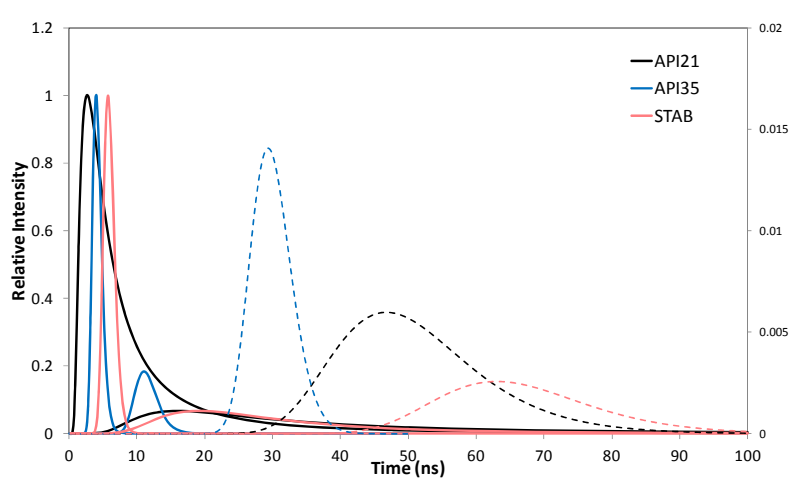

(d)

Figure 6. Probability distribution curves from analysis using Equation (4) with $\lambda_{\text {ex }}=300 \mathrm{~nm}$, (a) \& (b) diluted crue oil samples for $\lambda_{\text {em }}$ $=400 \mathrm{~nm} \& 450 \mathrm{~nm}$ respectively and (c) \& (d) undiluted samples for $\lambda_{\mathrm{em}}=400 \mathrm{~nm} \& 450 \mathrm{~nm}$ respectively. The dashed line curves are plotted on the secondary y-axis.

\subsection{Time-resolved fluorescence spectra}

Time-resolved emission spectra (TRES) were obtained for each of the samples exciting at a wavelength of $300 \mathrm{~nm}$. The emission spectra obtained for API35 in hexane is given in Figure 7. The data were fit globally to a 3 exponential model with lifetimes that are given in Table 4. In the case of the undiluted API21 (API21-N) sample it was necessary to fix the $5.71 \mathrm{~ns}$ component to obtain a reasonable fit to the data.

Table 4. Global fitted fluorescence lifetime parameters

\begin{tabular}{|ccccccc|}
\hline Crude Oil & API21 & API35 & STAB & API21-N & API35-N & STAB-N \\
\hline$\tau_{1} / \mathrm{ns}$ & $1.98 \pm 0.42$ & $1.58 \pm 0.42$ & $1.44 \pm 0.45$ & $0.62 \pm 0.15$ & $0.87 \pm 0.27$ & $1.04 \pm 0.21$ \\
$\tau_{2} / \mathrm{ns}$ & $5.55 \pm 0.33$ & $5.01 \pm 0.39$ & $5.15 \pm 0.39$ & $5.71(\mathrm{~F})$ & $4.72 \pm 0.86$ & $6.30 \pm 0.57$ \\
$\tau_{3} / \mathrm{ns}$ & $16.9 \pm 8.6$ & $13.1 \pm 3.8$ & $14.7 \pm 6.0$ & $31.4 \pm 3.0$ & $16.7 \pm 0.9$ & $24.6 \pm 0.9$ \\
$\chi^{2}$ & 0.87 & 0.93 & 0.69 & 1.22 & 0.85 & 1.01 \\
\hline
\end{tabular}

The variation in amplitude of the 3 components retrieved for API35 in hexane is shown in Figure 7. For comparison between the samples the relative amplitude of the $\tau_{2}$ component in Table 4 for each sample is compared and shown in Figure 8. The amplitude of each spectrum has been normalised to 1 at the peak value to allow for easier comparison between the spectra. For the diluted samples the maximum amplitude of the $\tau_{2}$ component is found at $\sim 360 \mathrm{~nm}$ with a shoulder / second peak observed at $400 \mathrm{~nm}$. The ratio of the peak heights is $1.11,0.82$ and 0.74 for API21, API35 and STAB crude respectively. For undiluted samples there is a large shift in the peak maximum wavelength to $\sim 425 \mathrm{~nm}$, with a much lower intensity peak observed at $\sim 360 \mathrm{~nm}$. 
The average lifetime for the crude oils recovered from the global analysis is plotted in Figure 9. The general shape of the curves for the diluted samples is the same with similar values being obtained for API35 and STAB crude. The average fluorescence lifetime for API21 is consistently higher at all emission wavelengths. The undiluted samples show a larger variation in the average fluorescence lifetime with emission wavelength. The shorter average lifetime values recovered at the lower emission wavelengths are consistent with a high percentage energy transfer occurring at the lower emission wavelengths. Interestingly there appears to be a significant increase in the average fluorescence lifetime at the longer emission wavelengths for API35-N and STAB-N which is not apparent in the API21-N oil.

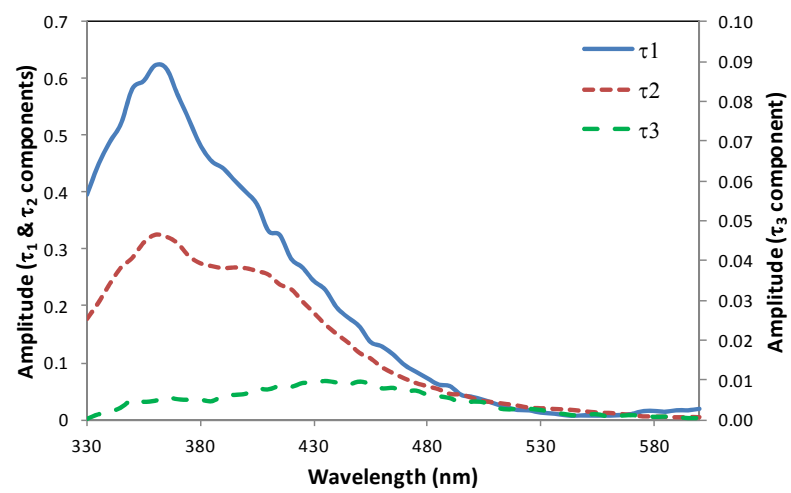

Figure 7. TRES for diluted API35 in hexane.

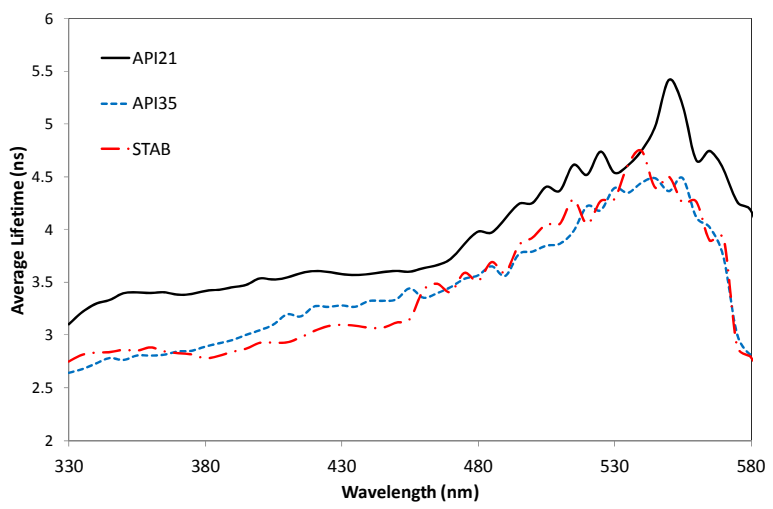

(a)

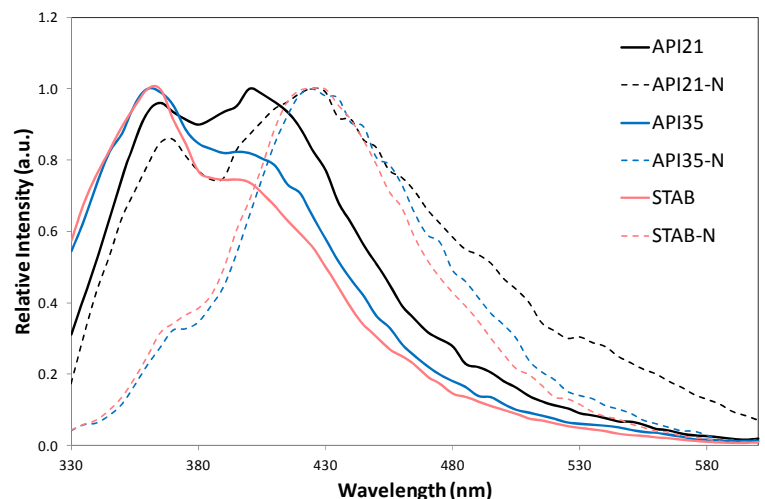

Figure 8. TRES for the $\tau_{2}$ component for the different crude oils investigated.

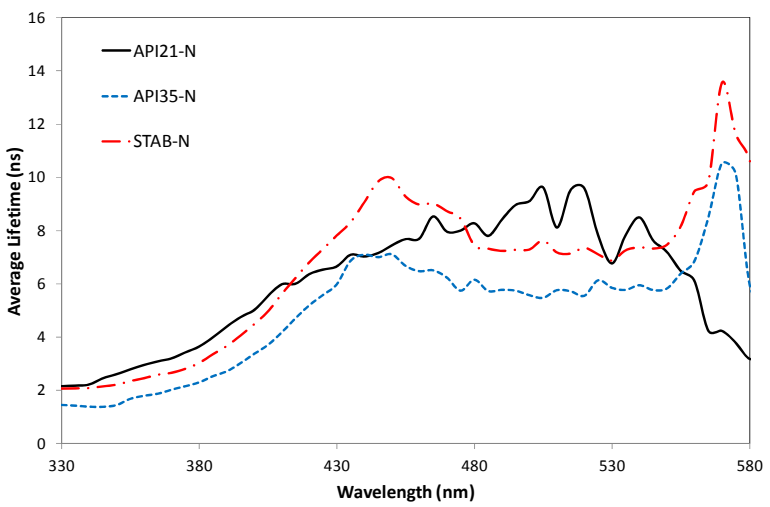

(b)

Figure 9. Average fluorescence lifetime for crude oil samples calculated from the TRES at each emission wavelength.

(a) Oils diluted in hexane (b) Undiluted oils

\section{CONCLUSION}

Crude oil fluorescence has been studied in dilute solutions in a range of solvents using second derivative synchronous scan fluorescence spectroscopy. Differences between the spectra recovered in different solvents indicate changes in the components dissolved in the different solvents and also the relative concentrations obtained. In most cases reported in the literature, dilution of crude oil is carried out in hexane. The results shown here indicate that comparison of spectra obtained using a variety of polar, non-polar, aromatic, and chlorinated solvents is useful for elucidating differences between crude oils through their fluorescence spectra, i.e. it may be possible to fingerprint crude oils.

Time-resolved studies of the crude oil samples have shown the application of a non-extensive distribution analysis to describe the decay kinetics. The fitted parameters obtained show clear differences between the crude oil samples studied and may be advantageous in highlighting the differences between source materials. Also the TRES highlight differences between the crude oils and the ratio of peaks for the $\tau_{2}$ component maybe a useful method for identifying crude oil samples. Future work aims to expand the database to include more crude oils. 


\section{ACKNOWLEDGEMENTS}

The authors would like to thank Dr Graham Hungerford, HORIBA Jobin Yvon (IBH) Ltd for use of the non-extensive distribution analysis software and for useful discussions on the interpretation of the data.

\section{REFERENCES}

[1] Downare, T. D. and Mullins, O. C. , "Visible and Near-Infrared Fluorescence of Crude Oils," Appl.Spectrosc. 49(6), 754-764 (1995).

[2] Pantoja, P. A., Lopez-Gejo, J., Le Roux, G. A. C., Quina, F. H. and Nascimento, C. A. O. , "Prediction of Crude Oil Properties and Chemical Composition by Means of Steady-State and Time-Resolved Fluorescence," Energy Fuels 25(8), 3598-3604 (2011).

[3] Ryder, A. G. , "Time-resolved fluorescence spectroscopic study of crude petroleum oils: Influence of chemical composition," Appl.Spectrosc. 58(5), 613-623 (2004).

[4] Ryder, A. G., Glynn, T. J., Feely, M. and Barwise, A. J. G. , "Characterization of crude oils using fluorescence lifetime data," Spectrochimica Acta Part A-Molecular and Biomolecular Spectroscopy 58(5), 1025-1037 (2002).

[5] Steffens, J., Landulfo, E., Courrol, L. C. and Guardani, R. , "Application of Fluorescence to the Study of Crude Petroleum," J.Fluoresc. 21(3), 859-864 (2011).

[6] Blamey, N. J. F., Conliffe, J., Parnell, J., Ryder, A. G. and Feely, M. , "Application of fluorescence lifetime measurements on single petroleum-bearing fluid inclusions to demonstrate multicharge history in petroleum reservoirs RID C-1297-2009," Geofluids 9(4), 330-337 (2009).

[7] Kim, M., Yim, U. H., Hong, S. H., Jung, J., Choi, H., An, J., Won, J. and Shim, W. J. , "Hebei Spirit oil spill monitored on site by fluorometric detection of residual oil in coastal waters off Taean, Korea RID C-2938-2008 RID B-8224-2009 RID B-8136-2009," Mar.Pollut.Bull. 60(3), 383-389 (2010).

[8] John, P. and Soutar, I. , "Identification of Crude Oils by Synchronous Excitation Spectrofluorimetry," Anal.Chem. 48(3), 520-524 (1976).

[9] Ryder, A. , "Assessing the maturity of crude petroleum oils using total synchronous fluorescence scan spectra RID C1297-2009," J.Fluoresc. 14(1), 99-104 (2004).

[10] Wang, X. and Mullins, O. C. , "Fluorescence Lifetime Studies of Crude Oils," Appl.Spectrosc. 48(8), 977-984 (1994).

[11] WIodarezyk, J. and Kierdaszuk, B. , "A new approach to interpretation of heterogeneity of fluorescence decay: Effect of induced tautorneric shift and enzyme -> ligand fluorescence resonance energy transfer," Biophys.Chem. 123(2-3), 146-153 (2006).

[12] Coelho, J., Hungerford, G. and Sooraj Hussain, N. , "Structural and time resolved emission spectra of Er(3+): Silver lead borate glass," Chemical Physics Letters 512(1-3), 70-75 (2011).

[13] Wlodarczyk, J. and Kierdaszuk, B. , "Interpretation of fluorescence decays using a power-like model," Biophys.J. 85(1), 589-598 (2003).

[14] Kierdaszuk, B. , "From discrete multi-exponential model to lifetime distribution model and power law fluorescence decay function," Spectroscopy-an International Journal 24(3-4), 399-407 (2010).

[15] Rolinski, O. J. and Birch, D. J. S. , "Nonextensive kinetics of fluorescence resonance energy transfer," J.Chem.Phys. 129(14), 144507 (2008).

[16] Ryder, A. G. , "Quantitative analysis of crude oils by fluorescence lifetime and steady state measurements using 380-nm excitation," Appl.Spectrosc. 56(1), 107-116 (2002). 